\title{
RELIABILITY ASSESSMENT USING UML MODELS
}

\section{JEDLICKA, M.; MORAVCIK, O.; SCHREIBER, P. \& TANUSKA, P.}

Abstract: This paper discusses the reliability estimation in early stages of software development process - analysis and design -using UML (Unified Modelling Language) models as the base for software system's specification. We introduce the last works done in this area and provide the critical overview of these approaches. Finally we present the results of our research and outline its directions for the future.

Key words: software reliability, software reliability assessment, Unified Modelling Language, UML Models
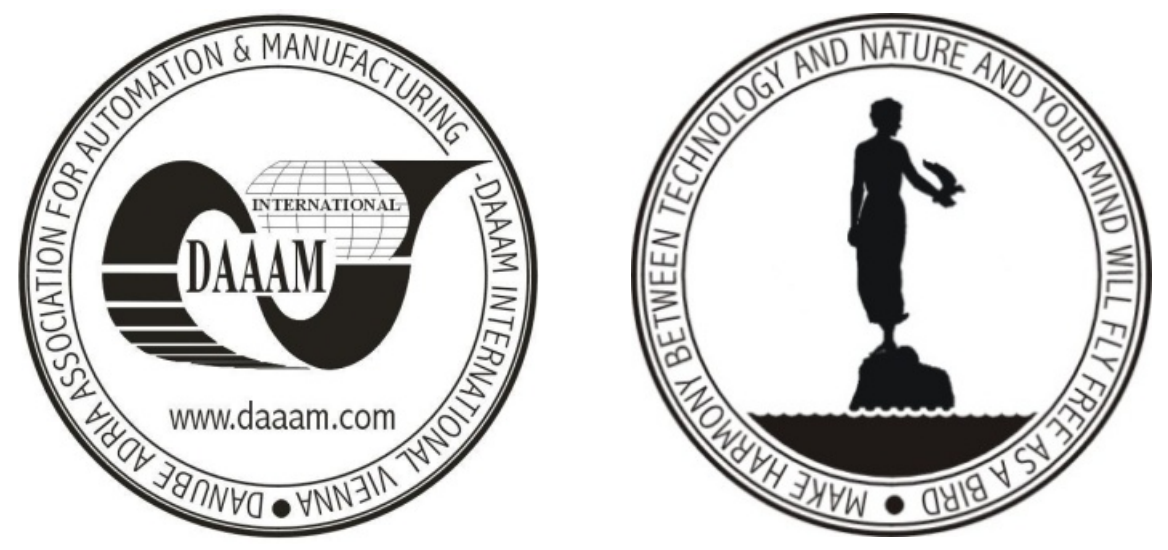

Authors' data: Ing. Jedlicka, M[artin]*; Prof. Dr. Ing. Moravcik, O[liver]**; doc. Ing. CSc., Schreiber, P[eter]**; doc. Ing. PhD. Tanuska, P[avol] ${ }^{* *}, *$ University of SS. Cyril and Methodius in Trnava, Námestie Jozefa Herdu 2, 91701, Trnava, Slovak Republic, ** Slovak University of Technology, Paulínska 16, 91724 Trnava, Slovak Republic, martin.jedlicka@qintec.sk, oliver.moravcik@stuba.sk, peter.schreiber@stuba.sk, pavol.tanuska@stuba.sk

This Publication has to be referred as: Jedlicka, M[artin]; Moravcik, O[liver]; Schreiber, P[eter] \& Tanuska, P[avol] (2009). Reliability Assessment Using UML Models, Chapter 07 in DAAAM International Scientific Book 2009, pp. 053-060, B. Katalinic (Ed.), Published by DAAAM International, ISBN 978-3-901509-69-8, ISSN 1726-9687, Vienna, Austria

DOI: 10.2507/daaam.scibook.2009.07 